\title{
A survey of anesthesia quality programs in Nova Scotia community hospitals
}

\author{
Oliver L. Hatheway, MD (1) · Gregory R. Dobson, MD • Andrew D. Milne, MD, MSc
}

Received: 22 November 2019/Revised: 26 November 2019/Accepted: 27 November 2019/Published online: 16 December 2019

(C) Canadian Anesthesiologists' Society 2019

\section{To the Editor,}

We read Pysyk, Filteau, and Baxter's review on quality and patient safety (QPS) committee activity at an academic centre with interest. ${ }^{1}$ The article highlighted the importance of QPS in anesthesia and provided a framework for other academic departments to model their own QPS activities after. While we are fortunate to have a similar structure and robust QPS process at our own academic institution, we were interested in understanding what QPS initiatives occur outside of the academic anesthesia setting.

In 2016, we conducted a provincial survey (Nova Scotia Health Authority Research Ethics Board approval \# 1021167) of quality improvement and quality assurance (QI/QA) activities at all seven of the non-tertiary regional hospitals that provide anesthesia services in Nova Scotia. A 13-item survey regarding QI/QA initiatives, staffing, support, and resources was distributed electronically (Opinio Survey Software, Oslo, Norway) and in paper form to the department heads at all the regional hospitals around the province. Reminder emails were sent electronically and by surface mail at one and three months to non-responding centres. The survey included a

Electronic supplementary material The online version of this article (https://doi.org/10.1007/s12630-019-01550-1) contains supplementary material, which is available to authorized users.

\section{O. L. Hatheway, MD}

Department of Anesthesiology, Perioperative \& Pain Medicine, University of Calgary, Calgary, AB, Canada

G. R. Dobson, MD - A. D. Milne, MD, MSc ( $\varangle)$ Department of Anesthesia, Pain Management and Perioperative Medicine, Dalhousie University, Halifax, NS, Canada

e-mail: admilne@dal.ca combination of qualitative and quantitative questions regarding QI/QA supports, staffing and infrastructure, and a checklist of 33 common anesthesia QI/QA indicators derived from the literature (eAppendix, available as Electronic Supplementary Material). Open free text responses surrounding general QI/QA initiatives and local practices were also collected. Narrative commentaries in the responses were analyzed for common themes. Given the limited number of hospitals in our province, we were unable to perform an initial pilot study to validate our survey items ${ }^{2}$ without reducing our sample size.

Five of the seven $(71 \%)$ provincial regional hospitals responded to our survey. All responding centres had some form of QI/QA program. The number of full-time equivalent anesthesia staff at each responding centre ranged from one to eight physicians. Morbidity and mortality rounds were the most common generalized QI/ QA activity amongst respondents $(3 / 5 ; 60 \%)$. The specific types of QI/QA indicators varied widely between sites. A total of 46 QI/QA indicators were tracked province-wide across the five respondent sites. These were distributed across the preoperative (7), intraoperative (19), and postoperative (20) domains. The most commonly tracked QI/QA indicators are listed in the Table.

Two respondent centres had a dedicated staffed QI/QA position, while some anesthesia QI/QA programs (2/5; $40 \%)$ were physician-led on a volunteer basis. Hospital administration or other departments in the hospital were also used by $2 / 5$ (40\%) of centres for QI/QA support. Three of the five centres $(60 \%)$ reported insufficient resources and time as barriers to QI/QA programs. Thematic analysis of the open text responses commonly indicated a strong interest in QI/QA, but identified lack of time, funding and expertise as barriers towards QI/QA activities. Selected anonymized responses along these themes included: 
Table Most commonly reported QI/QA initiatives monitored by respondent sites

\begin{tabular}{|c|c|c|}
\hline Preoperative initiatives & Intraoperative initiatives & Postoperative initiatives \\
\hline $\begin{array}{l}\text { Cancellations from preoperative } \\
\text { anesthesia clinic }(2 / 5)\end{array}$ & Allergic reaction $(2 / 5)$ & $\begin{array}{l}\text { Postoperative nausea and } \\
\text { vomiting }(2 / 5)\end{array}$ \\
\hline $\begin{array}{l}\text { Day of surgery cancellations by } \\
\text { anesthesia }(2 / 5)\end{array}$ & Malignant hyperthermia reaction $(2 / 5)$ & $\begin{array}{l}\text { Unexpected ICU admission or } \\
\text { admission of outpatients }(2 / 5)\end{array}$ \\
\hline \multirow{8}{*}{$\begin{array}{l}\text { Quality of preoperative anesthesia } \\
\text { assessments }(2 / 5)\end{array}$} & Aspiration $(2 / 5)$ & \\
\hline & Dental damage $(2 / 5)$ & \\
\hline & Failed airway $(2 / 5)$ & \\
\hline & Equipment malfunction $(2 / 5)$ & \\
\hline & Perioperative antibiotic administration (2/5) & \\
\hline & Drug errors/medication safety $(2 / 5)$ & \\
\hline & Massive transfusions $(2 / 5)$ & \\
\hline & Operating room time management $(2 / 5)$ & \\
\hline
\end{tabular}

Parentheses indicate the numbers of hospitals reporting the quality improvement/quality assurance (QI/QA) initiatives. ICU = intensive care unit

"I have advocated for 3 years... for a program that has many of these features"

"All of us in our department volunteer our time"

"Informal efforts toward QA/QI are made, but there is no dedicated time or funding"

"Lack of specific expertise; no time or funding for this important role."

Our survey clearly shows an interest in anesthesia QI/ QA programs in smaller regional centres in Nova Scotia, but also a need for more support and resources to implement these initiatives. While some may feel that the recent Canadian Anesthesiologists' Society practice guidelines $^{3}$ requirement for systematic monitoring of anesthesia quality is "daunting", 1 it may also provide impetus to help smaller anesthesia departments acquire support and infrastructure for QPS activities from hospital administrators. Although the Canadian Anesthesia Incident Reporting System (CAIRS) ${ }^{1,4}$ allows for reporting of anesthesia incidents, formation of a national network of QPS resources may help to reduce the workload on smaller anesthesia centres. These resources could include standardized QI/QA performance indicators (with CAIRS providing benchmarking rates), pre-built templates, tools or methods for data collection, online seminars and courses in anesthesia QPS, and continuous professional development/continuing medical education articles on anesthesia QPS through the Canadian Journal of Anesthesia.

A national network of QPS programs would provide an opportunity to share ideas and methodologies, as well as enhancing safety nationally rather than the current model of individual anesthesia departments working in siloed isolation. The recent paper by Pysyk et al. is to be applauded and could be the basis for the development of a Canadian network of QPS resources.

Conflicts of interest None.

Funding statement None.

Editorial responsibility This submission was handled by Dr. Hilary P. Grocott, Editor-in-Chief, Canadian Journal of Anesthesia.

\section{References}

1. Pysyk CL, Filteau L, Baxter A. Quality and patient safety committee structure and activities in an academic department of anesthesiology: a narrative description. Can J Anesth 2019. https:// doi.org/10.1007/s12630-019-01473-x.

2. Burns KE, Duffett $M$, Kho ME, et al. A guide for the design and conduct of self-administered surveys of clinicians. CMAJ 2008; 179: 245-52.

3. Dobson G, Chow L, Flexman A, et al. Guidelines to the practice of anesthesia - revised edition 2019. Can J Anesth 2019; 66: 75-108.

4. Beattie WS, Culwick MD, Grocott HP. Canadian Anesthesia Incident Reporting System (CAIRS): The Canadian Anesthesiologists' Society's National Patient Safety Initiative. Can J Anesth 2018; 65: 749-56.

Publisher's Note Springer Nature remains neutral with regard to jurisdictional claims in published maps and institutional affiliations. 